\title{
Creativity, Divergent Thinking, and Openness to Experience
}

\author{
Robert R. McCrae \\ Gerontology Research Center \\ National Institute on Aging, National Institutes of Health
}

\begin{abstract}
Test scores of divergent thinking obtained between 1959 and 1972 were correlated with a variety of personality measures administered since 1980. In this sample of 268 men, divergent thinking was consistently associated with self-reports and ratings of openness to experience, but not with neuroticism, extraversion, agreeableness, or conscientiousness. Both divergent thinking and openness were also modestly correlated with Gough's (1979) empirically derived Creative Personality Scale. Several other personality variables mentioned in the literature were also examined; those that were associated with divergent thinking were also generally correlated with openness. These data suggest that creativity is particularly related to the personality domain of openness to experience.
\end{abstract}

Although some object that the distinction is artificial (Heim, 1970), cognition and personality have traditionally been seen as distinct domains. Intelligence is construed as a set of aptitudes and abilities; personality is viewed, at least by psychometricians, as a collection of characteristic dispositions. Empirically, there is some justification for the separation. Measures of personality traits typically show very modest correlations with tests of general intelligence (e.g., Eysenck \& Eysenck, 1975), and joint factor analyses of personality and cognitive ability variables show that the latter form a distinct factor (McCrae \& Costa, 1985b, 1985c).

Creativity, however, seems to hold an intermediate position. The novelty and originality of creative productions imply both an ability to think fluently and flexibly and an inclination to do so. A voluminous literature has documented the importance of both these aspects of creativity (Barron \& Harrington, 1981). In this article, I attempt to organize the findings on personality characteristics associated with creativity by reference to a wellestablished taxonomy of personality traits. Specifically, I am testing the hypothesis that creativity is uniquely associated with the personality domain of openness to experience.

\section{Creativity, Intelligence, and Divergent Thinking}

Whether creativity should be considered part of general intelligence or a correlate of it or an entirely independent ability is still disputed. Sternberg (1985), for example, studied implicit theories of intelligence, creativity, and wisdom and concluded that "implicit theories are clearly inconsistent with views such as Guilford's (1967), according to which creativity is an aspect of intelligence" (p. 612). Measures of creativity and of intelligence are largely independent within specialized groups (e.g.,

Correspondence concerning this article should be addressed to Loring J. Ingraham, Laboratory of Psychology and Psychopathology, National Institute of Mental Health, Bethesda, Maryland 20892. architects, scientists) and are sometime uncorrelated in more diverse samples (Wallach \& Kogan, 1965). However, there is considerable evidence that creativity is strongly associated with intelligence when the full range of both variables is assessed. Highly creative individuals generally score very high on measured intelligence (Barron \& Harrington, 1981). When Sternberg (1985) created scales of intelligence and creativity based on implicit theories of each, they correlated substantially ( $r=$ .69 ) in a study rating letters of recommendation. Although conceptually discriminable, it appears that these two aptitudes are empirically closely related.

Cognitive studies of creativity have focused on divergent thinking abilities (Guilford, 1967). In contrast to the single correct answer demanded by convergent tests, divergent tests ask for as many appropriate answers as possible. Some tests emphasize the sheer quantity of productions: Word Fluency (Christensen \& Guilford, 1958b), for example, simply asks respondents to list as many words as they can that contain a specified letter. Other tests (e.g., Consequences; Christensen, Merrifield, \& Guilford, 1958) score for unusual and original responses. Factor analyses show that all these kinds of tests form a single factor, distinct from although related to general intelligence (McCrae, Arenberg, \& Costa, 1987).

As measures of creativity, divergent thinking tests have been widely criticized. Wallach and Kogan (1965), Harrington (1975), and Katz and Poag (1979) have shown that their validity is markedly influenced by the conditions under which they are administered, and Sternberg (1985) declined to use tests of creativity because he felt that "such tests capture, at best, only the most trivial aspects of creativity" (p. 618). Although tests like Word Fluency certainly have limited face validity as measures of creativity, their ability to identify creative individuals is an empirical matter, and in fact they are reasonably successful in this. As Barron and Harrington (1981) cautiously concluded, "some divergent thinking tests, administered under some conditions and scored by some sets of criteria, do measure abilities related to creative achievement and behavior in some domains" (p. 447). Consider an example: Alpaugh, Parham, Cole, and 
Birren (1982) had three English professors score stories written by 61 women, ages 20 to 83 , for originality and creativity. Interrater agreement between pairs of judges was quite high. ${ }^{1}$ The mean creativity ratings were significantly related to all the divergent thinking tests examined ( $r=.34$ to .55 ), and the observed relations could not be attributed to age or intelligence.

\section{Creativity and Personality}

Hundreds of studies have compared more and less creative individuals on measures of personality. Many have used the Adjective Check List (ACL; Gough \& Heilbrun, 1965); perhaps the most impressive of these studies pooled seven male and five female samples that had been rated for creativity (Gough, 1979). A 30-item Creative Personality Scale (CPS) was developed and cross-validated on samples that totaled over 1,700 subjects. Scales developed by the criterion-group strategy often include a conceptually diverse set of items, and some of the content of the CPS is puzzling. For example, individuals low in creativity described themselves as both affected and sincere; individuals high in creativity claimed to be both informal and snobbish. Most the the items, however, make sense: High scorers report that they are clever, inventive, reflective, and unconventional; low scorers endorse commonplace, conservative, and interests narrow. These items are also consistent with the personality characteristics repeatedly identified in the literature as correlates of creativity, including aesthetic sensitivity, broad interests, independence of judgment, and toleration of ambiguity (Barron \& Harrington, 1981).

It is possible to interpret most of these traits as components of a broad domain of personality that has been identified as openness to experience (McCrae \& Costa, 1985b). Factor analyses of questionnaires, adjective rating scales, and Q-sort items all point to a five-factor model of personality similar to the taxonomy offered in 1963 by Norman. Beyond Neuroticism, Extraversion, Agreeableness, and Conscientiousness is a fifth domain, Openness to Experience, which includes intellectual curiosity, aesthetic sensitivity, liberal values, and emotional differentiation. Adjectives from the Openness factor (McCrae \& Costa, 1985c) include conventional-original, down-to-earthimaginative, and uncreative-creative; California Q-Set (CQS; Block, 1961) items defining an Openness factor (McCrae, Costa, \& Busch, 1986) contrast values intellectual matters and rebellious, nonconforming with judges in conventional terms and favors conservative values. In questionnaire form (Costa \& McCrae, 1985b), openness is measured in areas of fantasy, aesthetics, feelings, actions, ideas, and values.

What all these elements share is an interest in varied experience for its own sake. Closed individuals are not necessarily defensive, but they are more comfortable with the familiar and have little incentive to try the new. Individuals closed to experience would have little motivation to be creative, and this might account for the repeated finding that individuals judged creative score high on traits in the domain of openness.

\section{Divergent Thinking and Openness}

Whether openness contributes to the ability to be creative is, however, a more difficult question. In an early study relating divergent thinking to personality scales, Merrifield, Guilford,
Christensen, and Frick (1961) reported very modest associations between fluency and originality and such variables as aesthetic interest, reflectiveness, and tolerance for ambiguity. There was no support for the hypotheses that originality would be related to nonconformity, need for adventure, or need for variety. A number of studies have correlated Rokeach's (1960) Dogmatism Scale-a measure of closedness-with measures of creative ability, with conflicting results (Parsons, Tittler, \& Cook, 1984). It is possible that openness to experience and divergent thinking abilities are independent predictors of creativity; certainly there are many individuals who have the desire to be creative but not the talent.

It is also possible, however, that the measurement of openness has been inadequate. Dogmatism, for example, may represent too small a part of the full domain of openness to show reliable relations. An alternative tradition of measuring openness began with Fitzgerald (1966), whose Experience Inquiry was intended to assess regression in the service of the ego (Kris, 1952). Revisions of this scale were subsequently made by Coan (1974) and Costa and McCrae (1978); the version to be used in this study is part of the NEO Personality Inventory (NEO-PI; Costa \& McCrae, 1985b), a questionnaire measure of the five major domains of personality.

In this study, I assess the relations among divergent thinking tests, Gough's CPS, and multiple measures of the five major domains of personality, especially openness to experience. Between 1959 and 1972, participants in the Baltimore Longitudinal Study of Aging (BLSA) were given a battery of divergent thinking tests; since 1980, many of the same individuals have been administered a variety of personality questionnaires and been the objects of peer and spouse ratings. Comparing cognitive performance with personality data collected 8 to 20 years later may seem questionable, but in fact there are good reasons to suspect that the lapse of time will have little effect on the relations observed. In the BLSA sample, the 6-year retest stability of total divergent thinking scores was .87 (McCrae et al., 1987), and personality traits are also known to be very stable in adulthood (McCrae \& Costa, 1984; see also Schaefer, 1972). Costa \& McCrae (1985a) have argued that, for many purposes, personality data collected at any point in adulthood may be considered contemporaneous, but it is also possible to view this design as a prospective longitudinal study that asks whether divergent thinking ability among adults predicts any aspect of personality a decade later.

A wealth of personality data has been accumulated on BLSA participants, and it seems appropriate here to test supplementary hypotheses about the relation of divergent thinking to other variables suggested by the literature. Woody and Claridge (1977) reported strong correlations between Wallach and Kogan's (1965) tests of creativity and Eysenck and Eysenck's (1975) Psychoticism Scale in a college sample, and Götz and Götz (1979) found that adult artists scored higher than controls on this dimension. Artistic interests, even among nonartists, have been associated with creativity, and Rump (1982) argued that Holland's (1985) measures of vocational interest may be useful predictors. Finally, Barron and Harrington (1981) sug-

\footnotetext{
'Compare Amabile's (1982) suggested definition: "A product or response is creative to the extent that appropriate observers independently agree that it is creative" (p. 1001).
} 
Table 1

Schedule of Administration of Measures

\begin{tabular}{|c|c|}
\hline Instrument & Date \\
\hline $\begin{array}{l}\text { Divergent thinking tests } \\
\text { Self-reports }\end{array}$ & December 1959 to August 1972 \\
\hline NEO Inventory & February 1980 \\
\hline California Q-Set sorts & August 1981 to January 1985 \\
\hline Self-Directed Search & October 1981 \\
\hline $\begin{array}{l}\text { Preliminary Agreeableness and } \\
\text { Conscientiousness scales, } \\
\text { adjective ratings, }\end{array}$ & \\
\hline psychoticism & March 1983 \\
\hline $\begin{array}{c}\text { Creative Personality Scale, } \\
\text { Sensation Seeking Scale V } \\
\text { Peer ratings: NEO Personality }\end{array}$ & September 1985 \\
\hline $\begin{array}{l}\text { Inventory, adjective ratings } \\
\text { Spouse ratings: NEO Inventory }\end{array}$ & $\begin{array}{l}\text { July } 1983 \\
\text { August } 1980\end{array}$ \\
\hline
\end{tabular}

gested that sensation seeking is among the traits that should be investigated as correlates of creativity, and a series of studies (see Zuckerman, 1979, pp. 238-240) have demonstrated significant positive correlations between early forms of Zuckerman's (1979) Sensation Seeking Scale (SSS-V) and a variety of measures of creativity and creative behavior. Some of these traits are themselves related to openness to experience; if creativity is uniquely related to openness, then those traits related to divergent thinking abilities should also be correlated with openness.

\section{Method}

\section{Subjects}

Subjects for the study were male volunteer participants in the BLSA (Shock et al., 1984). BLSA participants are a predominantly white, community-dwelling group of individuals who have agreed to return for periodic biomedical and psychological testing. Most have at least a college degree and work in or are retired from scientific, professional, or managerial occupations. Recruitment into the BLSA has been continuous, with most participants referred by friends or relatives already in the study. Although not representative of the general population in education or occupation, comparisons show that this sample does not differ markedly from a national sample with regard to the three personality dimensions of neuroticism, extraversion, and openness to experience (Costa et al., 1986).

As in most longitudinal studies, data have been gathered over a period of years, with new instruments introduced at different stages of the study. Table 1 gives the dates of administration of instruments analyzed in this article. Data were provided by 268 men given divergent thinking tests in the early years of the study and personality measures in recent years. They ranged in age from 18 to 80 at initial testing, with a mean age of 48.4 years. Because of missing data and participation in different aspects of the study, the number of subjects varies across analyses. Results are based on all available data; specific $N$ values are given in the tables.

\section{Measures and Procedures}

Divergent thinking tests. Six measures of divergent thinking were used: Associational Fluency I (Form A; Christensen \& Guilford, 1957a), in which subjects provide synonyms; Expressional Fluency (Form A; Christensen \& Guilford, 1958a), in which subjects write sen- tences with words beginning with designated letters; Ideational Fluency I (Form A; Christensen \& Guilford, 1957b), in which subjects name objects in specific classes; Word Fluency (Form A; Christensen \& Guilford, 1958b), in which subjects write words containing a designated letter, and Consequences (Christensen et al., 1958), in which subjects are required to imagine the possible consequences of unusual situations. The last of these is scored for Obvious and Remote Consequences, the latter being more unusual and original. A total score was also formed by summing standardized scores on the six tests. All tests were timed, and the order of administration of the fluency tests was counterbalanced. Because of time limitations, it was impossible for some subjects to complete the Consequences portion of the battery at the same visit; of the 268 subjects analyzed here, $86 \%$ took all tests at the same time, $8 \%$ took the Consequences portion at a later visit, and $6 \%$ failed to take the Consequences portion.

Because divergent thinking tests are open-ended, they cannot be objectively scored. Interscorer reliability, however, ranged from .96 to 1.00 for the four fluency tests. Interscorer reliability was .81 for Obvious Consequences and .74 for Remote Consequences. In these cases, judgment is needed not only to tally the number of appropriate and nonredundant responses but also to decide which are commonplace and which original; given the necessary subjectivity of these judgments, the observed reliabilities are reasonable. Internal-consistency estimates for the six tests ranged from .78 to .86 , and 6-year retest stability ranged from .63 to .81 . The 6-year stability coefficient for the total was .87 .

When the six divergent thinking tests were jointly factored with the eight subtests of the Army Alpha in the full BLSA sample (McCrae et al., 1987), all variables had positive loadings on the first, general factor. Because two eigenvalues were greater than 1.0, two varimax-rotated principal components were examined. All eight Army Alpha tests had their higher loading (ranging from .65 to .78) on the first factor, General Intelligence; all six divergent-thinking tests had their higher loading (.66 to .75) on the second factor, Fluency. These results suggest that the divergent thinking tests represent a relatively homogeneous cluster of cognitive abilities that are distinguishable from traditional measures of intelligence, and they support the use of a total score as a summary measure of divergent thinking.

Measures of the five-factor model. The NEO-PI is a 181-item questionnaire developed through factor analysis to fit a five-dimensional model of personality (Costa \& McCrae, 1985b). An earlier version of the test, the NEO Inventory (McCrae \& Costa, 1983a), measured traits in the three domains of neuroticism, extraversion, and openness to experience; this instrument was used for self-reports and spouse ratings. Recent modifications (McCrae \& Costa, 1987) have added two new scales to measure agreeableness and conscientiousness. Self-reports here are based on short, preliminary forms of the Agreeableness and Conscientiousness scales; full scales for these dimensions are used in peer ratings. Item scoring in the NEO-PI is balanced to control for acquiescence, and socially desirable responding does not appear to bias scores (McCrae \& Costa, 1983b). Internal consistency and 6-month retest reliability for the Neuroticism, Extraversion, and Openness scales range from .85 to .93 (McCrae \& Costa, 1983a); internal consistency for the Agreeableness and Conscientiousness scales are .89 and .91 , respectively, in peer ratings but somewhat lower in self-reports, where preliminary scales were used. The NEO-PI has been correlated with other inventories, observer ratings, and sentence completions and has been used to predict somatic complaints, psychological well-being, and coping behavior (Costa \& McCrae, 1985b).

Five factors were derived from an 80 -item adjective rating form in both self-reports (McCrae \& Costa, 1985c) and peer ratings (McCrae \& Costa, 1987). These factors were given the same labels as the domain scales of the NEO-PI and were significantly correlated with the questionnaire measures of the same construct. Five factors were also derived from the 100 items of the CQS (Block, 1961), which were sorted by subjects at their regularly scheduled visits to the Gerontology Research Center (McCrae et al., 1986). The CQS factors showed evidence of con- 
vergent and discriminant validity when correlated with the NEO-PI and the adjective factors.

All personality data except the CQS were collected through mail administrations. For approximately half the subjects, spouse ratings for neuroticism, extraversion, and openness were obtained on the NEO Inventory (McCrae, 1982). For a different subsample, peer ratings on the NEO-PI and adjective rating scales were obtained from men and women nominated by the subjects; one to four raters provided assessments. Details on the characteristics of the raters and their relationships to the subjects they rated are provided elsewhere (McCrae \& Costa, 1987). In general, the raters resembled the subjects in age and education and appeared to be well acquainted with them, having seen them frequently in a number of different situations for several years. Scores for peer ratings are averaged across raters.

Creative Personality Scale (Gough, 1979). The CPS is a 30 -item scale empirically derived from the 300 items of the ACL (Gough \& Heilbrun, 1965). Ratings of creativity from expert judges, faculty members, personality-assessment staff members, and life-history interviewers were examined for seven groups of men and five groups of women who had completed the ACL $(N=1,701)$. Correlations of individual items with creativity ratings were used to select 18 positive and 12 negative items. Internal-consistency coefficients in the derivation samples ranged from .73 to .81 . The CPS was significantly correlated with six other creativity scales previously derived from the ACL ( $r=.30$ to .76 ); in addition, it was correlated with creativity ratings in 10 of the 12 groups. In the two cross-validation samples, it showed correlations with rated creativity of $.35(N=35, p<.05)$ for men and $.40(N=35, p<.05)$ for women.

In this study, the 30 items were administered as a separate scale. To discourage differences in endorsement frequencies, subjects were instructed to "check about half (15) of the items." Internal consistency was .67 in this sample.

Other personality measures. Measures of several other personality variables sometimes linked to creativity have also been collected on BLSA participants (see Table 1). The EPQ Psychoticism scale (Eysenck \& Eysenck, 1975) is a 25-item scale intended to measure the normal personality dimension underlying psychotic and psychopathic disorders. Endorsement frequencies were low in this sample, and coefficient alpha was .47 (McCrae \& Costa, 1985a). The Self-Directed Search (SDS; Holland, 1985) is a widely used measure of vocational interests. Subsections on activities, competencies, occupations, and abilities were summed to form general interest scores for six areas: realistic, investigative, artistic, social, enterprising, and conventional (Costa, McCrae, \& Holland, 1984). The SSS-V (Zuckerman, 1979) consists of four subscales: Thrill and Adventure Seeking (in this sample, $\alpha=.80$ ), Experience Seeking ( $\alpha=.68$ ), Disinhibition ( $\alpha=.73$ ), and Boredom Susceptibility $(\alpha=.50)$.

\section{Results}

\section{Divergent Thinking and the Five-Factor Model}

The first seven columns of Table 2 present correlations of the divergent thinking tests with self-report and rating measures of the five personality domains. The pattern of results is unambiguous: Openness to Experience is positively related to all measures of divergent thinking except Obvious Consequences, whereas none of the other dimensions of personality shows any consistent relation to divergent thinking. When the differences of time and method are taken into consideration, these are impressive findings indeed: Scores on a measure of cognitive ability predict both self-reports and observer ratings of a personality disposition between 8 and 20 years later.

Obvious Consequences is here the exception that proves the rule. Common and unoriginal responses require certain cogni- tive skills (as the loading of Obvious Consequences on a general fluency factor shows), but they do not reflect creativity and are unrelated to openness. By contrast, novel responses give evidence of imaginativeness and unusual thought processes, and Remote Consequences is consistently related to measures of openness.

The pattern of results seen in Table 2 does not appear to be moderated by age. When dichotomized by age at time of cognitive testing ( 18 to 47 years vs. 48 to 80 years), very similar results were seen for younger and older men. The correlation of self-reported NEO-PI Openness with total divergent thinking was $.37(N=127, p<.001)$ for the former group and $.42(N=$ $123, p<.001$ ) for the latter; these correlations are not significantly different. Neuroticism, extraversion, agreeableness, and conscientiousness were unrelated to total divergent thinking in both groups.

In this sample, total divergent thinking scores were signifcantly associated with Wechsler Adult Intelligence Scale (WAIS) Vocabulary $(r=.53, N=247)$, age $(r=-.19, N=250)$, and years of education $(r=.52, N=237)$; NEO-PI Openness was also associated with these three variables. To examine the possibility that the associations between openness and divergent thinking might be due to these common influences, partial correlations were computed, simultaneously controlling for age at cognitive testing, years of education, and WAIS Vocabulary score. Although the association was diminished in magnitude, self-reported NEO-PI Openness to Experience was still significantly correlated with the total divergent thinking score $(r=.18, N=$ 234, $p<.01)$ as well as with Associational Fluency, Expressional Fluency, Word Fluency, and Remote Consequences. The partial correlation between total score and peer-rated openness was also significant $(r=.20, N=102, p<.05)$, although that with spouse-rated openness was not $(r=.05, N=102, n s)$.

To determine if personality traits are differentially related to creativity and intelligence, two residual scores were created: WAIS Vocabulary scores and age were partialed from total divergent thinking to yield a residual divergent thinking score, and total divergent thinking scores and age were partialed from WAIS Vocabulary to yield a residual vocabulary score. The correlations of these residual scores with personality measures are given in the eighth and ninth columns of Table 2 and show that residual divergent thinking is significantly correlated with four of the six measures of openness; residual vocabulary is significantly related to openness in two cases. The only other replicated finding is a negative correlation between residual vocabulary and extraversion (in three cases). In this well-educated sample, it appears that both creativity and intelligence are related to openness, whereas intelligence independent of creativity is associated with introversion.

Table 3 gives the correlations of divergent thinking tests with the six facets of openness measured in the NEO-PI. Again with the exception of Obvious Consequences, most of the correlations are statistically significant for each facet of openness; apparently divergent thinking abilities are associated with all forms of openness, not merely intellectual curiosity and openness to ideas. When corresponding correlations are examined in spouse and peer ratings, a similar pattern is seen: $29(85 \%)$ of the 34 significant correlations in Table 3 are replicated ( $p<$ .05 , one-tailed) in either peer or spouse ratings, and $14(41 \%)$ are replicated in both. 
Table 2

Correlations of Divergent Thinking Tests and Creative Personality Scale (CPS) With Self-Reports and Ratings on Measures of the Five-Factor Model

Residuals

Divergent thinking tests

\begin{tabular}{|c|c|c|c|c|c|c|c|c|c|c|}
\hline Factor & & $\begin{array}{l}\text { Divergent } \\
\text { thinking }\end{array}$ & Vocabulary & CPS \\
\hline \multicolumn{11}{|c|}{ NEO Personality Inventory } \\
\hline \multicolumn{11}{|c|}{ Self-reports } \\
\hline Extraversion & -.03 & .04 & .06 & .02 & $.13^{*}$ & $.13^{*}$ & .09 & $.13^{*}$ & $-.24^{* * * *}$ & $.30^{* * *}$ \\
\hline Openness & $.38 * * *$ & $.30^{* * *}$ & $.25^{* * *}$ & $.33^{* * * *}$ & .06 & $.34^{* * * *}$ & $.39^{* * *}$ & $.18^{* *}$ & $.20^{* *}$ & $.44^{* * *}$ \\
\hline Agreeableness & .04 & .02 & .03 & .05 & .04 & .01 & .05 & .01 & .11 & $.17^{*}$ \\
\hline Neuroticism & -.10 & -.04 & .03 & .02 & -.12 & .10 & -.01 & -.13 & .11 & .11 \\
\hline Extraversion & .12 & .13 & .15 & .12 & -.04 & .10 & .16 & .18 & -.17 & $.37^{* * * *}$ \\
\hline Openness & $.37 * * *$ & $.36^{* * *}$ & $.28 * *$ & $.37^{* * *}$ & -.05 & $.29 * *$ & $.41^{* * *}$ & $.26 * *$ & .18 & $.34 * *$ \\
\hline Agreeableness & .03 & .03 & -.10 & -.10 & -.06 & -.14 & -.07 & -.06 & .14 & $-.39 * * *$ \\
\hline Conscientiousness & .06 & -.04 & .00 & .05 & .08 & -.02 & .02 & .10 & -.01 & -.02 \\
\hline \multicolumn{11}{|l|}{ Spouse ratings } \\
\hline Neuroticism & .05 & -.07 & -.02 & -.03 & $-.20^{*}$ & .03 & -.06 & -.07 & .02 & -.14 \\
\hline Extraversion & $-.14^{*}$ & -.02 & $-.15^{*}$ & -.12 & -.03 & -.11 & $-.15^{*}$ & -.02 & $-.29^{* * * *}$ & .16 \\
\hline Openness & $.37^{* * * *}$ & $.28 * * * *$ & $.28^{* * * *}$ & $.39^{* * *}$ & .11 & $.27^{* * *}$ & $.39 * * *$ & $.25^{\text {**** }}$ & .11 & $.61^{\text {*k** }}$ \\
\hline Agreeableness & $.16^{*}$ & .04 & -.09 & .07 & -.13 & -.04 & .02 & .02 & .01 & -.11 \\
\hline Conscientiousness & -.02 & -.05 & .01 & .02 & .06 & .05 & .00 & .01 & -.01 & $.30^{* * *}$ \\
\hline \multicolumn{11}{|l|}{ Peer ratings } \\
\hline Neuroticism & .05 & .11 & .11 & $.18^{*}$ & -.08 & .15 & .14 & .01 & .16 & .05 \\
\hline Extraversion & -.02 & .05 & .04 & -.07 & -.05 & .00 & .03 & .06 & -.14 & $.26^{*}$ \\
\hline Openness & $.27^{* *}$ & $.27^{* *}$ & $.26^{* *}$ & $.39^{* * *}$ & .06 & $.40^{* * * *}$ & $.40^{* * *}$ & $.30^{* *}$ & .11 & $.38^{\text {*m* }}$ \\
\hline Agreeableness & .05 & -.02 & -.10 & -.07 & -.08 & -.13 & -.07 & -.06 & .14 & $-.30^{* *}$ \\
\hline \multirow{2}{*}{\multicolumn{11}{|c|}{$\begin{array}{l}\text { California Q-Set factor scores } \\
\text { (self-reports) }\end{array}$}} \\
\hline & & & & & & & & & & \\
\hline Neuroticism & -.05 & $-.22 * *$ & $-.20^{*}$ & -.01 & -.11 & -.01 & -.14 & -.17 & .10 & $-.36^{* * * *}$ \\
\hline
\end{tabular}

Note. For divergent thinking tests, $n s=130-267$ with self-reports, $105-115$ with peer ratings, and $104-113$ with spouse ratings; for CPS, $n s=86-$ 137 with self-reports, 81 with peer ratings, and 65 with spouse ratings. AF $=$ Associational Fluency; EF $=$ Expressional Fluency; IF $=$ Ideational Fluency; $\mathrm{WF}=$ Word Fluency; $\mathrm{OC}=$ Obvious Consequences; $\mathrm{RC}=$ Remote Consequences.

${ }^{*} p<.05{ }^{* *} p<.01 .^{* * *} p<.001$.

Table 3

Correlations of Divergent Thinking Tests With Facets of Openness on the NEO Personality Inventory

Divergent thinking tests

\begin{tabular}{|c|c|c|c|c|c|c|c|}
\hline Self-reports & AF & EF & IF & WF & $\mathrm{OC}$ & RC & Total \\
\hline Fantasy & $.22^{* * *}$ & $.19^{* *}$ & .07 & $.19^{* *}$ & .00 & $.21^{* * * *}$ & $.21^{* * *}$ \\
\hline Aesthetics & $.27^{\text {*⿻一未丷 }}$ & $.20^{* * *}$ & $.16^{* *}$ & $.15^{\star}$ & -.01 & $.18^{* *}$ & $.23^{* \ldots *}$ \\
\hline Actions & .10 & $.16^{* *}$ & .06 & $20^{* * *}$ & .02 & $.17^{* * *}$ & $.17^{* *}$ \\
\hline Ideas & $.33^{* * * *}$ & $20^{* *}$ & $.27^{* * *}$ & $.27^{\text {****}}$ & .05 & $.22^{* * * *}$ & $.31^{\text {*** }}$ \\
\hline Values & $.21^{\text {****}}$ & $.15^{*}$ & $.20^{* * * *}$ & $.19^{* *}$ & .04 & $.27^{* * *}$ & $.25^{\text {****}}$ \\
\hline
\end{tabular}

Note. $N=250-267 . \mathrm{AF}=$ Associational Fluency; $\mathrm{EF}=$ Expressional Fluency; IF $=$ Ideational Fluency; $\mathrm{WF}=$ Word Fluency; $\mathrm{OC}=\mathrm{Obvious}$ Consequences; $\mathbf{R C}=$ Remote Consequences.

${ }^{*} p<.05 .{ }^{* *} p<.01$. ${ }^{* * *} p<.001$. 
Table 4

Correlations of Other Personality Variables With Openness to Experience and Total Divergent Thinking Score

\begin{tabular}{lcc}
\hline \multicolumn{1}{c}{ Variable } & $\begin{array}{c}\text { Openness } \\
\text { to experience }\end{array}$ & $\begin{array}{c}\text { Total divergent } \\
\text { thinking }\end{array}$ \\
\hline EPQ Psychoticism & -.06 & .00 \\
Self-Directed Search & & \\
Realistic & $.17^{*}$ & $-.16^{*}$ \\
Investigative & $.34^{* * *}$ & $.24^{* *}$ \\
Artistic & $.50^{* * *}$ & $.27^{* * *}$ \\
Social & $.16^{*}$ & $.19^{*}$ \\
Enterprising & .11 & .10 \\
Conventional & -.06 & -.02 \\
Sensation Seeking Scale V & & $.22^{* *}$ \\
Thrill and Adventure Seeking & $.32^{* * *}$ & $.25^{* * *}$ \\
Experience Seeking & $.51^{* * *}$ & $.22^{* *}$ \\
Disinhibition & $.25^{* *}$ & $.18^{*}$ \\
Boredom Susceptibility & .15 & $.31^{* * *}$ \\
$\quad$ Total Sensation Seeking & $.45^{* * *}$ & \\
\hline
\end{tabular}

Note. $N=156-201 . \mathrm{EPQ}=$ Eysenck Personality Questionnaire.

${ }^{*} p<.05{ }^{* *} p<.01 .^{* * *} p<.001$.

\section{Creative Personality Scale}

The bottom row of Table 2 gives the correlations of the CPS with divergent thinking tests. All (except that with Obvious Consequences) are statistically significant but modest in magnitude, suggesting that the CPS and divergent thinking tests are related but distinguishable indicators of creativity. The CPS shows a small negative correlation with age $(r=-.18, p<.05)$ and a small positive correlation with years of education $(r=.17$, $p<.05)$, but is unrelated to WAIS Vocabulary $(r=.09, n s)$. Controlling for these three variables leaves a partial correlation of $.17(N=141, p<.05)$ between CPS scores and total divergent thinking.

The last column of Table 2 gives correlations of the CPS with measures of the five-factor model of personality. The diverse item content of the CPS is reflected in the range of significant correlations. Neuroticism is negatively related to CPS scores in two of the six cases, suggesting that creative individuals may be better adjusted than others. Extraversion (in four cases) and conscientiousness (in three of five cases) are positively related, suggesting that creative persons are also more energetic, sociable, and achievement-oriented. No consistent relation is seen to agreeableness, which is positively related to the CPS in NEOPI self-reports but negatively related in peer ratings. However, openness is significantly positively related to CPS scores in all six cases, with correlations ranging from .26 to .61 . Individuals who score high on the CPS see themselves and are seen by spouses and peers as being high in openness to experience. ${ }^{2}$

\section{Other Personality Variables}

Table 4 gives correlations of other personality variables with NEO-PI Openness and total divergent thinking scores. Psychoticism is unrelated to both Openness and divergent thinking. In this sample, it appears instead to measure the low poles of the two dimensions of Agreeableness and Conscientiousness (McCrae \& Costa, 1985a). ${ }^{3}$

As hypothesized, artistic interests are significantly related to divergent thinking abilities, as are investigative and, to a lesser extent, social interests; all these interests are also associated with openness. Neither openness nor divergent thinking is related to enterprising or conventional interests. Thus, individuals who prefer occupations such as anthropologist, independent research scientist, author, composer, sociologist, and social science teacher are apt to show more cognitive flexibility and fluency and more dispositional openness than are those who prefer the occupations of sports promoter, salesperson, bank teller or inventory controller. Realistic interests, which are positively related to openness but negatively related to divergent thinking, show an exception to the general pattern. The small positive correlation with openness is probably attributable to the fact that open individuals have broad interests that include outdoor and mechanical as well as artistic and investigative occupations. People who are interested exclusively in realistic occupations are, as a group, probably neither open nor highly creative (cf. Costa et al., 1984).

As in previous work (Zuckerman, 1979), total Sensation Seeking is significantly related to divergent thinking; it is also correlated with Openness. Of the four subscales, Experience Seeking is most strongly related to both Openness and divergent thinking. Boredom Susceptibility, however, is significantly related to divergent thinking but not to Openness.

\section{Discussion}

In an attempt to organize the literature on creativity and personality, two putative indicators of creativity - divergent thinking tests and Gough's (1979) CPS—were correlated with multiple measures of a comprehensive taxomony of personality traits, the five-factor model. The CPS was most strongly and consistently related to openness to experience, although it was also correlated with (low) neuroticism, extraversion, and conscientiousness. Divergent thinking abilities as measured in this study were consistently related only to openness. These findings might be viewed as support for the hypothesis that creativity is uniquely related to openness to experience.

There is mixed evidence, however, that traits outside the domain of openness are also systematically related to creative abilities. The correlations of the CPS suggest that creative people are adjusted, sociable, and productive as well as open. Although there is no support for this interpretation from the divergent thinking data, it is possible that different results would have

\footnotetext{
${ }^{2}$ To replicate these findings, the Creative Personality Scale (CPS) was correlated with the same personality measures in a sample of female participants in the Baltimore Longitudinal Study of Aging ( $N s=45$ to 142). Among women, the CPS showed significant negative correlations with three of the six measures of neuroticism and positive correlations with four measures of extraversion and all six measures of openness to experience. None of the correlations with Agreeableness or Conscientiousness reached statistical significance. Again, these results suggest that high CPS scorers are adjusted, extraverted, and particularly open to experience.

${ }^{3}$ The Psychoticism scale was not administered as part of the full Eysenck Personality Questionnaire (EPQ), so correlations with EPQ Neuroticism and Extraversion are not available. However, total divergent thinking was not significantly related to the Neuroticism or Extraversion measures of the Eysenck Personality Inventory, which was administered to the sample earlier.
} 
been obtained if the tests had been administered under other conditions. Harrington (1975) and Katz and Poag (1979) found that the psychological meaning of divergent thinking test scores changed when subjects were specifically instructed to be creative. In Harrington's study, correlations with an ACL measure of creative abilities increased from .22 in the standard condition (comparable to the .26 found between total divergent thinking and the CPS in this study) to .64 in the creativity condition. Scorers high in divergent thinking in the creativity condition, but not in the standard condition, described themselves as selfconfident, dominant, and achievement-oriented. These traits are consistent with the CPS finding that more creative individuals are adjusted, extraverted, and conscientious as well as open.

Studies of rated creativity often but not always support these contentions. Helson's (1985) women nominated for creative potential and Barron's (1969) creative female mathematicians could be described as open and extraverted, but whereas Helson's subjects were characterized by high conscientiousness, Barron's were regarded as less dependable and responsible than were representative (i.e., noncreative) female mathematicians. Barron's (1969) study of originality in Irish managers suggests that creativity in this context is marked chiefly by disagreeableness, as seen in such adjectives as cynical and bossy as opposed to pleasant and unselfish. Katz and Poag (1979) found that women scoring high in divergent thinking tests under instructions to be creative labeled themselves as cold, timid, and cowardly.

As Barron and Harrington (1981) pointed out, there is some variation in personality characteristics across fields of creative endeavor. Painters may be high in psychoticism (Götz \& Götz, 1979); creative scientists may be more introverted than creative salesmen. These differences may account for some of the conflicting literature. In addition, creative ability does not inevitably lead to recognized creativity, and a variety of personality traits may be involved in being perceived as creative. Conscientious individuals may complete their creative projects more often; extraverts may exhibit them more readily; adjusted individuals may be less distracted from creative work by personal problems. At this point, it seems reasonable to conclude that openness to experience is a common characteristic of creative individuals but that additional research is needed to ascertain whether and under what conditions other domains of personality contribute to creative accomplishments.

It has often been pointed out that dispositions and abilities interact in the life of the individual (e.g., Heim, 1970). Smart extraverts make intelligent conversation, smart introverts read difficult books; conscientious individuals use their intellectual gifts, lackadaisical individuals do not. Openness to experience and divergent thinking abilities may also interact as mutually necessary conditions for creativity, the former providing the inclination and the latter providing the aptitude for original thinking. But these two are not independent predictors of creativity; they are themselves consistently related, and the explanation for this association is a matter of some interest. There are several possibilities.

First, open and closed individuals may differ not in true divergent thinking ability but merely in test performance. The open person may be intrigued by the task of imagining consequences or generating words that include a specified letter and thus outperform the closed person. By provision of extrinsic motivation (such as money), closed individuals might be induced to perform as well as open individuals do on divergent thinking tasks. Experimental studies could be designed to test this possibility.

Second, open people may have developed intellectual and especially divergent thinking abilities through a lifetime of practice. By exercising their cognitive faculties, they may have discovered or retained skills that were lost to closed individuals. If this process occurs, it should be cumulative, and it might be expected that the association of openness with divergent thinking would be stronger in older than in younger men. When younger and older men in this sample were examined separately, however, correlations were not significantly different. Similar comparisons in children, adolescents, and young adults might find support for this mechanism at an earlier age.

Finally, the appreciation of novelty may be facilitated by the ability to think creatively. Individuals who easily generate new ideas, whose cognitive processes are flexible, may develop an interest in varied experience, just as individuals with particular competencies develop corresponding vocational interests (Holland, 1985). Again, developmental studies could clarify these issues.

Unfortunately, the most scientifically satisfying way of discovering the causal ordering of these two variables is not feasible. Both personality traits and cognitive abilities are singularly resistant to experimental manipulation, at least with interventions known today. In the immediate future, therefore, openness to experience may be of more value as a means of selecting potentially creative individuals than as a mechanism for enhancing creativity.

\section{References}

Alpaugh, P. K., Parham, I. A., Cole, K. D., \& Birren, J. E. (1982). Creativity in adulthood and old age: An exploratory study. Educational Gerontology, 8, 101-116.

Amabile, T. M. (1982). Social psychology of creativity: A consensual assessment technique. Journal of Personality and Social Psychology, 43, 997-1013.

Barron, F. (1969). Creative person and creative process. New York: Holt, Rinehart \& Winston.

Barron, F., \& Harrington, D. M. (1981). Creativity, intelligence, and personality. Annual Review of Psychology, 32, 439-476.

Block, J. (1961). The $Q$-sort method in personality assessment and psychiatric research. Springfield, IL: Charles C Thomas.

Christensen, P. R., \& Guilford, J. P. (1957a). Associational Fluency I, Form A. Beverly Hills, CA: Sheridan Supply.

Christensen, P. R., \& Guilford, J. P. (1957b). Ideational F/uency I, Form $A$. Beverly Hills, CA: Sheridan Supply.

Christensen, P. R., \& Guilford, J. P. (1958a). Expressional Fluency, Form A. Beverly Hills, CA: Sheridan Supply.

Christensen, P. R., \& Guilford, J. P. (1958b). Word Fluency, Form A. Beverly Hills, CA: Sheridan Supply.

Christensen, P. R., Merrifield, P. R., \& Guilford, J. P. (1958). Consequences, Form A-II. Beverly Hills, CA: Sheridan Supply.

Coan, R. W. (1974). The optimal personality. New York: Columbia University Press.

Costa, P. T., Jr., \& McCrae, R. R. (1978). Objective personality assessment. In M. Storandt, I. C. Siegler, \& M. F. Elias (Eds.), The clinical psychology of aging (pp. 119-143). New York: Plenum Press.

Costa, P. T., Jr., \& McCrae, R. R. (1985a). Concurrent validation after 20 years: Implications of personality stability for its assessment. In J. N. Butcher \& C. D. Spielberger (Eds.), Advances in personality assessment (Vol. 4, pp. 31-54). Hillsdale, NJ: Erlbaum. 
Costa, P. T., Jr., \& McCrae, R. R. (1985b). The NEO Personality Inventory manual. Odessa, FL: Psychological Assessment Resources.

Costa, P. T., Jr., McCrae, R. R., \& Holland, J. L. (1984). Personality and vocational interests in an adult sample. Journal of Applied Psychology, $69,390-400$.

Costa, P. T., Jr., McCrae, R. R., Zonderman, A. B., Barbano, H. E., Lebowitz, B., \& Larson, D. M. (1986). Cross-sectional studies of personality in a national sample: II. Stability in neuroticism, extraversion, and openness. Psychology and Aging, 1, 144-149.

Eysenck, H. J., \& Eysenck, S. B. G. (1975). Manual of the Eysenck Personality Questionnaire. San Diego, CA: Educational and Industrial Testing Service.

Fitzgerald, E. T. (1966). Measurement of openness to experience: A study of regression in the service of the ego. Journal of Personality and Social Psychology, 4, 655-663.

Götz, K. O., \& Götz, K. (1979). Personality characteristics of professional artists. Perceptual and Motor Skills, 49, 327-334.

Gough, H. G. (1979). A creative personality scale for the Adjective Check List. Journal of Personality and Social Psychology, 37, 13981405.

Gough, H. G., \& Heilbrun, A. B., Jr. (1965). Adjective Check List manual. Palo Alto, CA: Consulting Psychologists Press.

Guilford, J. P. (1967). The nature of human intelligence. New York: McGraw-Hill.

Harrington, D. M. (1975). Effects of explicit instructions to "be creative" on the psychological meaning of divergent thinking test scores. Journal of Personality, 43, 434-454.

Heim, A. (1970). Intelligence and personality: Their assessment and relationship. Baltimore: Penguin Books.

Helson, R. (1985). Which of those young women with creative potential became productive? Personality in college and characteristics of parents. In R. Hogan \& W. H. Jones (Eds.), Perspectives in personality (Vol. 1, pp. 49-80). Greenwich, CT: JAI Press.

Holland, J. L. (1985). Self-Directed Search-1985 edition. Odessa, FL: Psychological Assessment Resources.

Katz, A. N., \& Poag, J. R. (1979). Sex differences in instructions to "be creative" on divergent and nondivengent test scores. Joumal of Personality, 47, 518-530.

Kris, E. (1952). Psychoanalytic explorations in art. New York: Intemational Universities Press.

McCrae, R. R. (1982). Consensual validation of personality traits: Evidence from self-reports and ratings. Journal of Personality and Social Psychology, 43, 293-303.

McCrae, R. R., Arenberg, D., \& Costa, P. T., Jr. (1987). Declines in divergent thinking with age: Cross-sectional, longitudinal, and crosssequential analyses. Psychology and Aging, 2, 130-137.

McCrae, R. R., \& Costa, P. T., Jr. (1983a). Joint factors in self-reports and ratings: Neuroticism, extraversion, and openness to experience. Personality and Individual Differences, 4, 245-255.

McCrae, R. R., \& Costa, P. T., Jr. (1983b). Social desirability scales:
More substance than style. Journal of Consulting and Clinical Psychology, 51, 882-888.

McCrae, R. R., \& Costa, P. T., Jr. (1984). Emerging lives, enduring dispositions: Personality in adulthood. Boston: Little, Brown.

McCrae, R. R., \& Costa, P. T., Jr. (1985a). Comparison of EPI and Psychoticism scales with measures of the five factor model of personality. Personality and Individual Differences, 6, 587-597.

McCrae, R. R., \& Costa, P. T., Jr. (1985b). Openness to experience. In R. Hogan \& W. H. Jones (Eds.), Perspectives in personality (Vol. 1, pp. 145-172). Greenwich, CT: JAI Press.

McCrae, R. R., \& Costa, P. T., Jr. (1985c). Updating Norman's “adequate taxonomy": Intelligence and personality dimensions in natural language and in questionnaires. Journal of Personality and Social Psychology, 49, 710-721.

McCrae, R. R., \& Costa, P. T., Jr. (1987). Validation of the five-factor model of personality across instruments and observers. Journal of Personality and Social Psychology, 52, 81-90.

McCrae, R. R., Costa, P. T., Jr., \& Busch, C. M. (1986). Evaluating comprehensiveness in personality systems: The California Q-Set and the five factor model. Journal of Personality, 54, 430-446.

Merrifield, P. R., Guilford, J. P., Christensen, P. R., \& Frick, J. W. (1961). Interrelationships between certain abilities and certain traits of motivation and temperament. Journal of General Psychology. 65, 57-74.

Norman, W. T. (1963). Toward an adequate taxonomy of personality attributes: Replicated factor structure in peer nomination personality ratings. Journal of Abnormal and Social Psychology, 66, 574-583.

Parsons, R. J., Tittler, B. I., \& Cook, V. J. (1984). A multi-trait multimethod evaluation of creativity and openness. Psychological Reports, 54, 403-410.

Rokeach, M. (1960). The open and closed mind. New York: Basic Books.

Rump, E. E. (1982). Relationships between creativity, arts-orientation, and esthetic-preference variables. Journal of Psychology, 110, 11-20.

Schaefer, C. E. (1972). Follow-up study of a creativity scale for the Adjective Check List. Psychological Reports, 30, 662.

Shock, N. W., Greulich, R. C., Andres, R., Arenberg, D., Costa, P. T., Jr., Lakatta, E. G., \& Tobin, J. D. (1984). Normal human aging: The Baltimore Longitudinal Study of Aging (NIH Publication No. 842450). Bethesda, MD: National Institutes of Health.

Sternberg, R. J. (1985). Implicit theories of intelligence, creativity, and wisdom. Journal of Personality and Social Psychology, 49, 607-627.

Wallach, M. A., \& Kogan, N. (1965). Modes of thinking in young children. New York: Holt, Rinehart \& Winston.

Woody, C., \& Claridge, G. S. (1977). Psychoticism and thinking. British Journal of Social and Clinical Psychology, 16, 241-248.

Zuckerman, M. (1979). Sensation seeking: Beyond the optimal level of arousal. New York: Erdbaum.

Received July 16, 1986

Revision received October 17, 1986 Accepted January 9, 1987 